\title{
Disturbance in the Substrate Balance Related to Insulin Resistance and Diabetes Mellitus Type 2
}

\section{Fabiano De Macedo Salgueirosa and Maria Gisele Dos Santos*}

Department of Physical Education, Federal University of Paraná, Curitiba, PR, Brazil

*Corresponding Author: Maria Gisele Dos Santos, Department of Physical

Education, Federal University of Paraná, Curitiba, PR, Brazil.
Received: March 23, 2020

Published: May 11, 2020

(C) All rights are reserved by Fabiano De

Macedo Salgueirosa and Maria Gisele Dos Santos.

\section{Introduction}

Diabetes Mellitus (DM) is considered today as one of the biggest public health problems. It is estimated that in 2030 approximately 366 million people will have some type of DM [1]. Type 2 DM (DM2) is caused mainly by insulin resistance, defined by Hunter and Garvey [2] as "a clinical condition in which a normal or elevated concentration of insulin is observed that produces an attenuated biological response", manifesting itself 10 - 20 years before the symptoms of DM2 are observed.

In the years before the onset of DM2 symptoms, despite insulin resistance being observed, there is an increase in insulin secretion, that is, compensatory hyperinsulinemia, maintaining normal glycemic concentrations until dysfunctions occur in beta cells and inability to control glycemia leading to thus to the diagnosis of DM2 [3].

Lipid metabolism during exercise

Lipids represent the most abundant source of energy for the body. Triacylglycerols (TAG) are stored in adipose tissue $(\sim 17,500$ mmol in a lean adult male), in skeletal muscle $(\sim 300 \mathrm{mmol})$ and in plasma ( $\sim 0.5 \mathrm{mmol}$ ) [4] making TAG is an important source of energy for the muscle during contraction. The amount of TAG available in the body would be sufficient, for example, for a continuous run at a marathon pace for 120 hours [5].

To be used as an energy source by muscles, free fatty acids (FFA) need to be hydrolyzed (from adipose tissue, muscle or plasma) in a process called lipolysis and then carried by the plasma to the cells where they will be oxidized within the mitochondria.

In adipose tissue, fatty acids are stored in the form of TAG. Lipolysis is controlled by the action of some hormones: mainly by the concentrations of adrenaline and norepinephrine (which can stimulate lipolysis through $\beta$-adrenergic receptors or inhibit lipolysis through $\alpha$-adrenergic receptors) and by insulin which has an inhibitory effect on lipolysis (Figure 1) [6]. Thus, increases in circulating catecholamine concentrations resulting from exercise stimulate lipolysis.

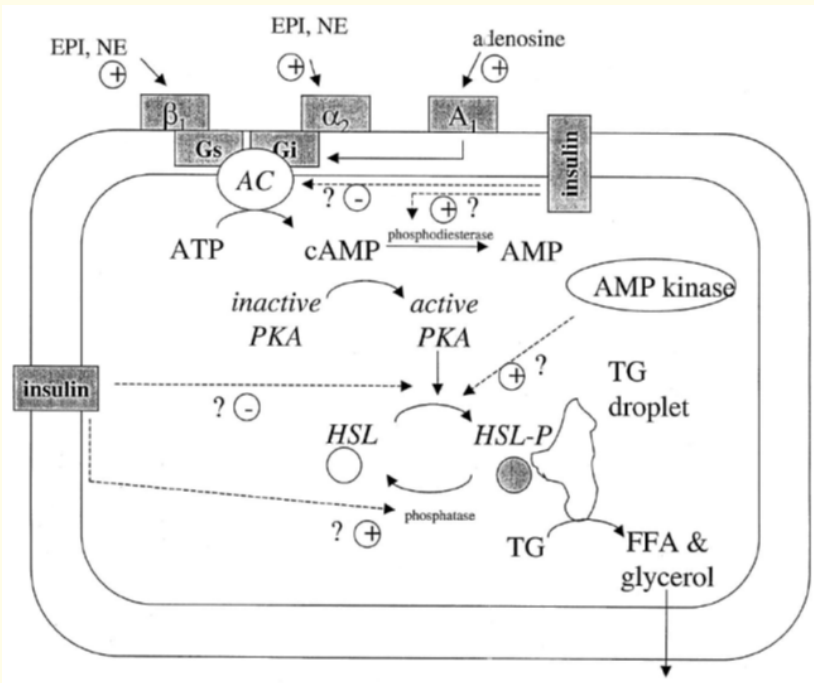

Figure 1: Regulation of lipolysis. Source: Spriet [7].

Catecholamines bind to adrenergic receptors in adipocytes and stimulate through adenylate cyclase a second messenger: cyclic AMP which in turn activates PKA (protein kinase A) leading to phosphorylation of HSL (hormone-sensitive lipase) [6,7]. The complete hydrolysis of TAG to glycerol and AGL occurs in three consecutive reactions, catalyzed by two enzymes: HSL that catalyzes the hydrolysis of triacylglycerols and diacylglycerols and monoacylglycerol (MGL) lipase, which is required for the complete hydrolysis of monoacylglycerols [8].

Insulin inhibits lipolysis by activating phosphodiesterase 3B (PDE3B) which leads to a reduction in cyclic AMP concentrations and a reduction in PKA activity [6].

After complete hydrolysis, FFAs passively pass through the adipocyte membrane or mediated proteins associated with the membrane such as fatty acid translocase (FAT) or fatty acid transport protein (FATP) and move if by the way they are linked to albumin, they pass through the capillary wall and again bind to circulating albumin and can be transported to tissues such as muscle [9]. 
Reaching the muscle cell, the FFA must cross the membrane to be metabolized. Until recently it was believed that this transport to the interior of the cell occurred by passive diffusion through the cell membrane, however today there is strong evidence that this most of the FFA that enter the muscle cell is transported by a carrier system $[7,9]$.

According to Spriet [7] in the last few years three fatty acid transport proteins have been identified and cloned: the fatty acid transport protein present in the plasma membrane (FABPpm - fatty acid binding protein in the plasma membrane), the translocase fatty acid (FAT - fatty acid) translocase) and the fatty acid transport protein (FATP - fatty acid transport protein).

The first step in the capture of plasma fatty acids is translocation through the luminal membrane, the cytoplasmic compartment and through the albumin membrane of the endothelial cell. Then the fatty acids need to be transported through the interstitial space linked to the albumin. So, the fatty acids need to be transported through the sarcolemma. This transport can occur by passive diffusion or linked to FABPpm or by proteins in the membrane (FAT and FATP). In the cytoplasm, fatty acids are linked to a cytoplasmic carrier protein: FABPc and carried to the mitochondria to be oxidized [9].

The entry of fatty acids into the mitochondria is mediated by the carnitine palmitoyl transferase (CPT) complex. This basically consists of three proteins linked to the mitochondrial membrane: CPT I, acyl-carnitine translocase and CPT II. CPT I is located on the outer surface of the outer membrane of the mitochondria and is responsible for the first step in transporting the fatty acid into the mitochondria: catalyzing the acyl groups of CoA to carnitine, forming acyl-carnitine. Acyl-carnitine can then permeate the interior of the mitochondrial membrane via acyl-carnitine translocase and be moved into the mitochondria and converted to acyl-CoA by CPT II located on the inner surface of the inner membrane of the mitochondria. Acyl-CoA can then enter the $\beta$-oxidation pathway for ATP re-synthesis $[7,10]$.

\section{Carbohydrate metabolism during exercise}

Muscle glycogen and blood glucose are important substrates for the ATP re-synthesis in active muscle during exercise [11] and their contribution to the total energy demand increases according to the intensity of the exercise.

In the body, carbohydrates are stored mainly in the form of muscle and liver glycogen.

To be used as an energy source for the muscle during contraction, carbohydrates must first be converted into glucose [12]. In the case of the use of glycogen, it needs to be converted into glucose in a process called glycogenolysis.

The enzyme glycogen phosphorylase, which is considered one of the key enzymes of carbohydrate metabolism, catalyzes the first step in the breakdown of glycogen [11] and its action is regulated by the action of catecholamines adrenaline and norepinephrine through the activation of cAMP and stimulation of calcium that convert the less active form (phosphorylase b) into the more active form (phosphorylase a) [13].

The breakdown of muscle glycogen is faster during the initial stages of exercise with its utilization rate being exponentially related to the intensity of the exercise, due to the increase in circulating catecholamines, and declines with the continuity of the exercise as the availability of glycogen decreases [11].

The glycogen is broken down to form 1-phosphate glucose and this is converted to 6-phosphate glucose by the enzyme phosphoglycutase. When blood glucose is used as a substrate, after being captured by GLUTs, it must also be converted into glucose 6-phosphate. This reaction is catalyzed by the hexokinase enzyme [13].

After the 6-phosphate glucose is formed whatever the source (blood glucose or muscle glycogen), it goes through a series of reactions until the formation of pyruvate that can follow the aerobic or anaerobic pathway (Figure 2).

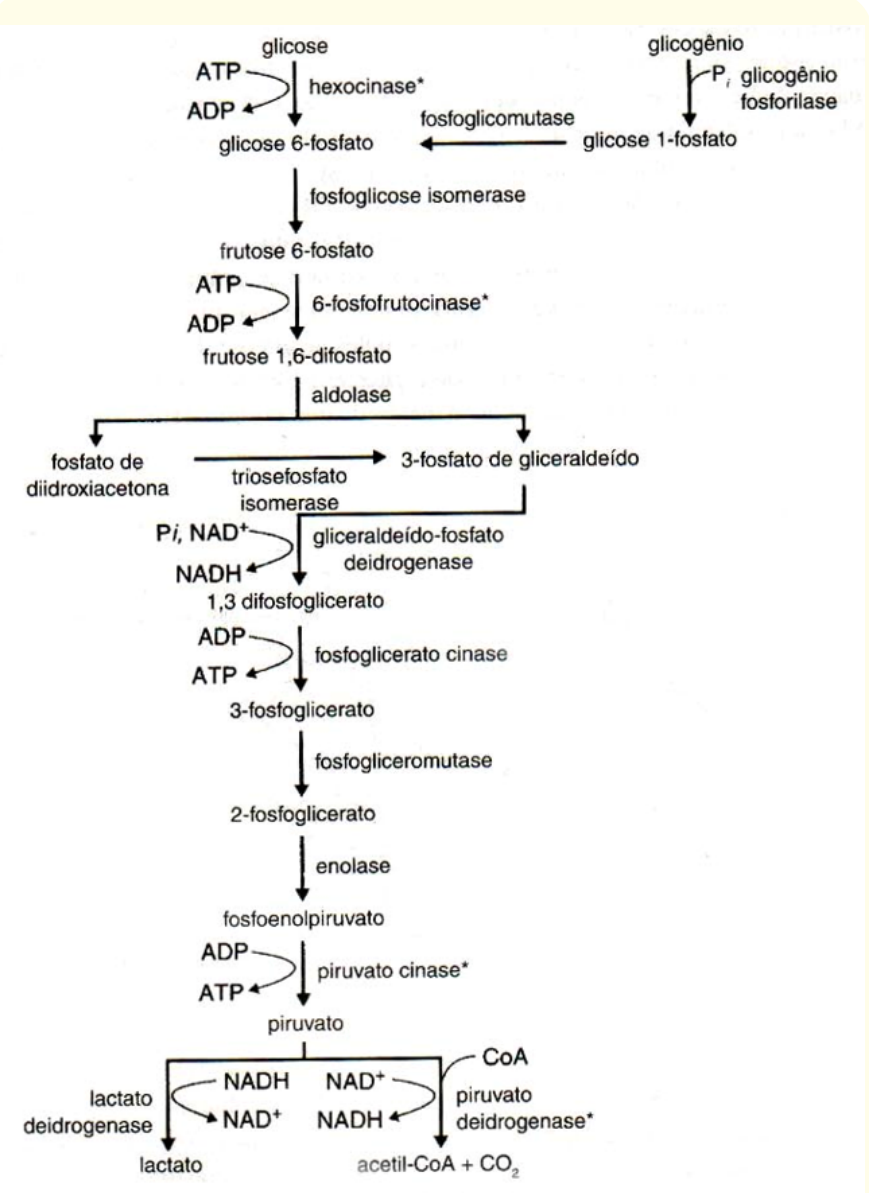

Figure 2: Glycolysis reactions. Source: Maughan., et al [13].

Among these reactions, the conversion of fructose 1-phosphate to fructose 1,6-phosphate, catalyzed by the enzyme phosphofructokinase (PFK), stands out. PFK is one of the most intensively studied 
regulatory enzymes [14] and one of the key enzymes in the regulation of glycolysis [13].

PFK activity is regulated by the concentration of a series of metabolic intermediates, including: fructose 6-phosphate, fructose 1,6-phosphate, ATP, ADP, AMP, hydrogen ions, citrate and ammonium [14]. The biggest regulator of PFK activity is the cell's energy status [11]. It is inhibited by intracellular concentrations of ATP and phosphocreatine, which means that activity is low when the cell is full of energy, but high when the cell's energy load is low [13].

In addition to the visible importance of carbohydrates as a direct source of ATP for muscle contraction during exercise, they are also vitally important for the generation of substrates that supply the tricarboxylic acid (TCA) cycle [11], which has become important also for fat metabolism during exercise.

\section{Substrate selection during the exercise}

According to Powers and Howley [15] proteins contribute less than $2 \%$ of the substrate used in the exercise with less than 1 hour of duration, having only a small role as substrate in the exercise, with carbohydrates and fats serving as the main sources of energy of a healthy individual who consumes a balanced diet.

Also, according to the same author, the selection of the substrate used during exercise mainly depends on: the diet, the intensity and the duration of the exercise.

During exercise of increasing intensity, the relative contribution of carbohydrate oxidation to energy expenditure increases with a corresponding reduction in the contribution of fat oxidation [16]. This shift in the predominance of energy sources in relation to the intensity of the exercise (Figure 3) was called the crossover point. The crossing point is identified as the intensity at which the energy derived from the oxidation of carbohydrate-based fuels (muscle and liver glycogen, blood glucose and lactate) predominates over fat derivatives (adipose and intramyocellular triglycerides, as well as fatty acids blood triglycerides) [17].

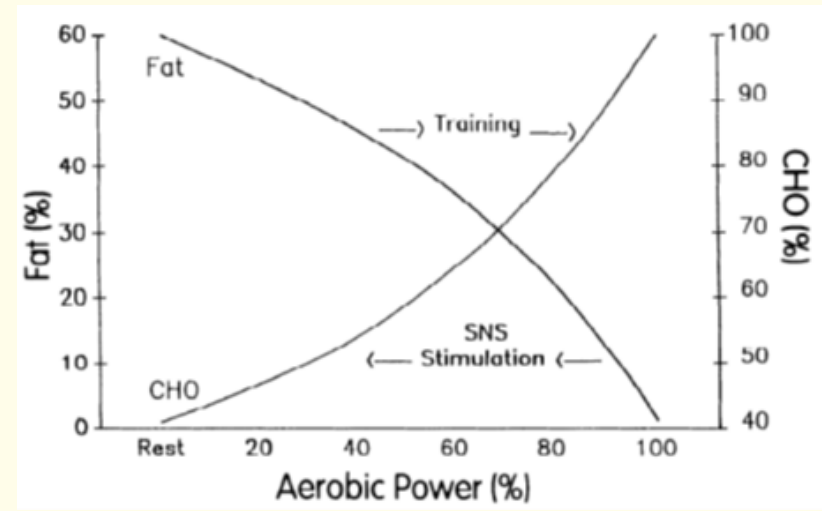

Figure 3: The crossover point. Source: Brooks and Mercier [17].
This shift in predominance of energetic substrates according to the intensity of the exercise occurs mainly due to two factors: 1) recruitment of fast fibers. Since, with the increase in exercise intensity, the participation of fast-twitch fibers increases and they have a large amount of glycolytic enzymes, that is, more prepared to metabolize carbohydrates; and 2) increased blood concentrations of adrenaline. As the intensity increases, adrenaline concentrations rise, which in turn stimulate glycogen degradation, glycolysis and, consequently, lactate production. Lactate in turn inhibits lipolysis.

Exercise duration is also an important factor for substrate selection during exercise. Over time during exercise there is a gradual increase in the use of fats and a reduction in the use of carbohydrates. This is probably due to the increase in catecholamine concentrations during prolonged exercise stimulating lipases and the reduction in insulin concentrations [15].

Disturbances in the substrate balance related to insulin and DM2 resistance

In recent years, several researchers have investigated the substrate balance related to insulin resistance, or DM2 and obesity.

Colberg., et al. [18] compared the total oxidation of fats and carbohydrates with indirect calorimetry and use of blood glucose with methods of diluting isotopes at rest and during a cycle ergometer exercise in 3 groups (lean, obese and obese type 2 diabetics) (40 minutes to $40 \%$ of $\mathrm{VO}_{2} \max$ ). Although the total oxidation of fats and carbohydrates was not different between groups, the oxidation of glycogen was lower and blood glucose was higher in type 2 diabetics when compared to the other groups.

Similar results were found by Borghouts., et al. [19] in nonobese type 2 diabetics. DM2 patients had a significantly lower rate of glycogen oxidation and higher blood glucose oxidation than the control group during exercise (60 minutes on cycle ergometer at $40 \% \mathrm{VO}_{2} \mathrm{max}$ ). Regarding the total oxidation rate of fats and carbohydrates, there were no significant differences.

In another study Blaak., et al. [20] verified the oxidation of substrates using indirect calorimetry and infusion of palmitate isotopes during rest and exercise (60 minutes on a cycle ergometer at $50 \%$ of $\mathrm{VO}_{2} \max$ ) in obese type 2 diabetics and in one control group of non-diabetic obese individuals. There were no significant differences in the total oxidation of fats and carbohydrates during rest and exercise. Diabetic subjects showed significantly less oxidation of plasma fatty acids and greater fatty acids derived from triglycerides. In this study, the contribution of different sources of carbohydrates was not measured.

It is important to note that in the three studies mentioned, the subjects had DM2, therefore, hyperglycemia and the movement of glucose from the blood to the tissues may have been facilitated by the mass action [21]. 
In order to study possible changes in the use of substrate due to insulin resistance, without the influence of hyperglycemia and differences in body composition Braun., et al. [21] studied insulinresistant women, however with normal, overweight and obese glycemia during 50 minutes of walking on a treadmill at $45 \%$ of $\mathrm{VO}_{2}$ máx. A significant reduction in total carbohydrate utilization was observed in the insulin resistant group.

\section{Conclusion}

In view of these results, the authors argued that alterations in the substrate balance can be attributed to insulin resistance and not to the presence of excess fat. Among the possible explanations, the authors stressed that if individuals had a high level of intramyocellular triglycerides, the use of carbohydrates could have been reduced by the greater availability of fats.

\section{Bibliography}

1. Wild S., et al. "Global prevalence of diabetes: estimates for the year 2000 and projections for 2030". Diabetes Care 27.5 (2004): 1047-1053.

2. Hunter SJE and Garvey WT. "Insulin action and insulin resistance: diseases involving defects in insulin receptors, signal transduction, and the glucose transport effector system". The American Journal of Medicine 105.4 (1998): 331-345.

3. Cefalu WT. "Insulin resistance: cellular and clinical concepts". Experimental Biology and Medicine 226.1 (2001): 13-26.

4. Horowitz JF and E Klein S. "Lipid metabolism during endurance exercise". The American Journal of Clinical Nutrition 72.2 (2000): 558S-563S.

5. Frayn KN. "Regulation of fatty acid delivery In vivo". In: EA Richter, B Kiens, H Galbo and B Saltin (Ed.). Skeletal muscle metabolism in exercise and diabetes". New York: Plenum Press (1998).

6. Holm C., et al. "Molecular mechanisms regulating hormonesensitive lipase and lipolysis". Annual Review of Nutrition 20 (2000): 365-393.

7. Spriet LL. "Regulation of skeletal muscle fat oxidation during exercise in humans". Medicine and Science in Sports and Exercise 34.9 (2002): 1477-1484.

8. Lima FB., et al. "Entendendo a gordura. Os ácidos graxos". Barueri: Manole (2002).

9. Jeukendrup AE., et al. "Fat metabolism during exercise: a review. Part I: fatty acid mobilization and muscle metabolism". International Journal of Sports Medicine 19.4 (1998): 2312244.

10. Jeukendrup AE. "Regulation of fat metabolism in skeletal muscle". Annals of the New York Academy of Sciences 967 (2002): 217-235.

11. Hargreaves M. "Skeletal muscle carbohydrate metabolism during exercise". In: M. Hargreaves (Ediion.). Exercise metabolism. Champaign: Human Kinetics (1995).
12. Wilmore JHE and Costill DL. "Fisiologia do esporte e do exercício". São Paulo: Manole (2001).

13. Maughan R., et al. "Bioquímica do exercício e do treinamento". São Paulo: Manole (2000).

14. Stanley WCE and Connett RJ. "Regulation of muscle carbohydrate metabolism during exercise". The FASEB Journal 5.8 (1991): 2155-2159.

15. Powers SKE and Howley ET. "Fisiologia do exercício: Teoria e aplicação ao condicionamento e ao desempenho". Barueri: Manole (2000).

16. Achten J., et al. "Determination of the exercise intensity that elicits maximal fat oxidation". Medicine and Science in Sports and Exercise 34.1 (2002): 92-97.

17. Brooks GA and E Mercier J. "Balance of carbohydrate and lipid utilization during exercise: the "crossover" concept". Journal of Applied Physiology 76.6 (1994): 2253-2261.

18. Colberg SR., et al. "Utilization of glycogen but not plasma glucose is reduced in individuals with NIDDM during mild-intensity exercise". Journal of Applied Physiology 81.5 (1996): 20272033.

19. Borghouts LB., et al. "Substrate utilization in non-obese Type II diabetic patients at rest and during exercise". Clinical Science 103.6 (2002): 559-566.

20. Blaak EE., et al. "Impaired oxidation of plasma-derived fatty acids in type 2 diabetic subjects during moderate-intensity exercise". Diabetes 49.12 (2000): 2102-2107.

21. Braun B., et al. "Effects of insulin resistance on substrate utilization during exercise in overweight women". Journal of Applied Physiology 97.3 (2004): 991-997.

\section{Assets from publication with us}

- Prompt Acknowledgement after receiving the article

- Thorough Double blinded peer review

- Rapid Publication

- Issue of Publication Certificate

- High visibility of your Published work

Website: https://www.actascientific.com/

Submit Article: https://www.actascientific.com/submission.php Email us: editor@actascientific.com

Contact us: +919182824667 